\title{
Chikungunya in the Caribbean: An Epidemic in the Making
}

\author{
Lizette Mowatt $\cdot$ Sandra T. Jackson
}

To view enhanced content go to www.infectiousdiseases-open.com

Received: July 29, 2014 / Published online: September 23, 2014

(C) The Author(s) 2014. This article is published with open access at Springerlink.com

\section{ABSTRACT}

Chikungunya is a mosquito-borne virus that has shown increased prevalence in the Caribbean since October 2013. There have been several outbreaks throughout Asian and African countries over the past few decades with global travel and tourism having a major impact on the further spread of this disease. Improved policies and practices for preventative measures and epidemiological surveillance must be implemented to prevent the continued transmission of chikungunya.

Keywords: Aedes aegypti; Aedes albopictus; Caribbean; Chikungunya virus (CHIKV); Dengue fever; Jamaica; Saint Martin

Electronic supplementary material The online version of this article (doi:10.1007/s40121-014-0043-9) contains supplementary material, which is available to authorized users.

L. Mowatt ( $\square)$

Department of Surgery, Anesthetics, Radiology and Intensive Care, University of the West Indies, Mona, Jamaica

e-mail: lizettemowatt@yahoo.com

S. T. Jackson

Virology Division, Microbiology Department,

University of the West Indies, Mona, Jamaica

\section{INTRODUCTION}

A member of the Togaviridae family, infection with the chikungunya virus (CHIKV) has emerged as a major public health concern, resulting in outbreaks of fever and debilitating arthralgia in the Caribbean and globally [1]. The first autochthonous (native) transmission of CHIKV in the Caribbean was confirmed in December 2013 on the French island of Saint Martin [2]. Rapid spread and local transmission of CHIKV occurred in the Caribbean and the Americas within 9 months (Fig. 1). This has resulted in 651,344 suspected and 9,182 laboratory-confirmed chikungunya cases in the Caribbean and the Americas as reported by the Centers for Disease Control and Prevention [3]. The effective management of the rapid spread of chikungunya is integrally related to the geographic distribution and re-emergence of competent mosquito vectors, evolving CHIKV genotypes, susceptible human populations, environmental influences, and social mobilization [4]. Understanding the contribution of these factors is important to improving the control of the global transmission of this disease. 


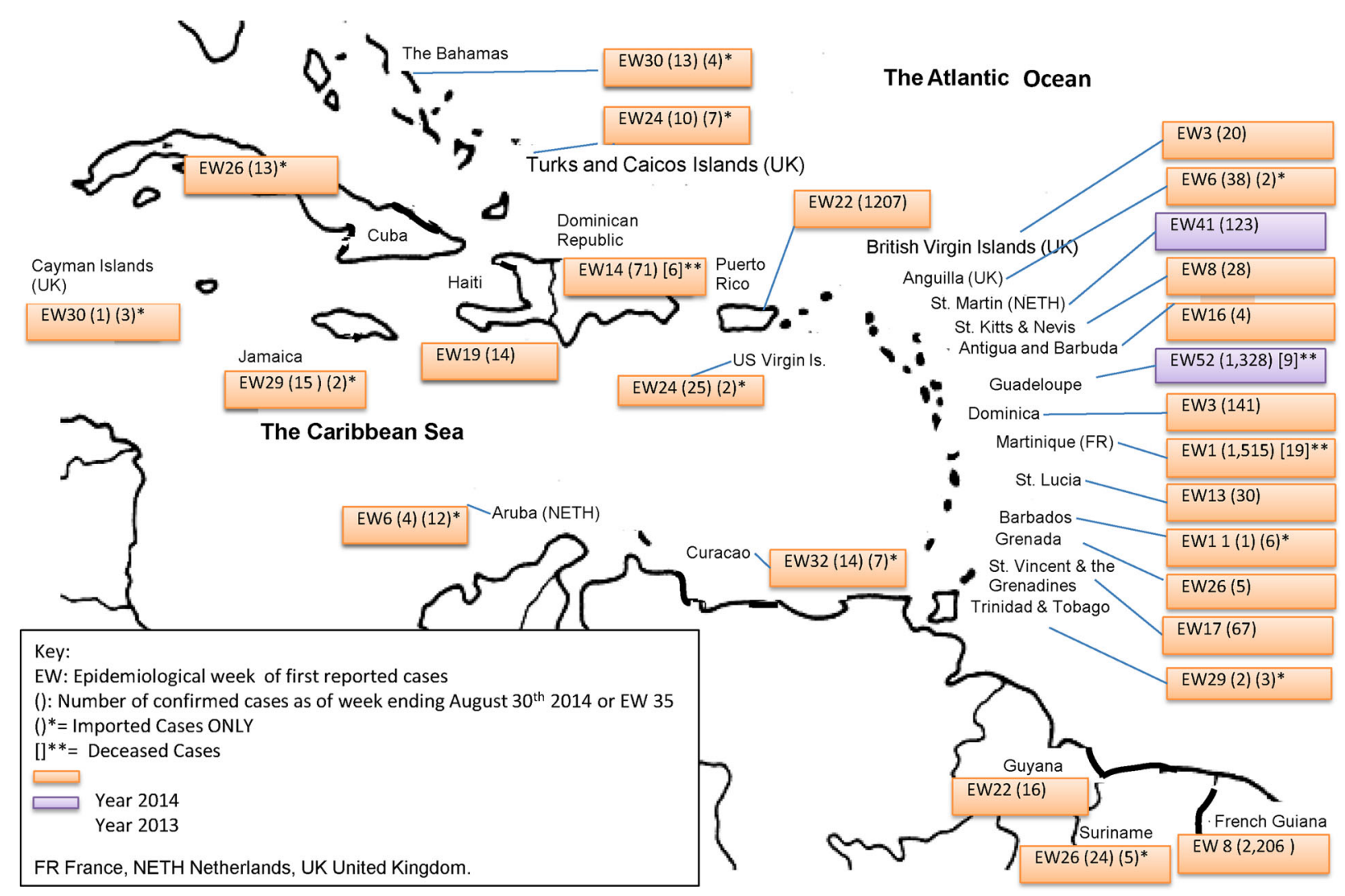

Fig. 1 Introduction of chikungunya to the Caribbean by epidemiological week first reported-December 2013 to August 2014. Data from PAHO/WHO statistics [26]

\section{THE GEOGRAPHIC SPREAD OF CHIKUNGUNYA GENOTYPES}

There are three distinct CHIKV genotypes: West African, East Central South African [ECSA; or Indian Ocean lineage (IOL)], and Asian $[1,5,6]$. These genotypes represent the evolution of the virus in keeping with the geographic distribution over the years. In Africa, this virus is transmitted through enzootic (sylvatic) and urban (human-mosquito cycle) cycles among non-human and human primates by Aedes mosquitoes species. Previous authors report the probable existence of the CHIKV in Africa for hundreds of years, with the first suspected epidemic documented in 1779 [7]. Subsequent reports included outbreaks in Nigeria (1964), the Ivory Coast (1981), and Senegal (1983) associated with the West African strain [6]. The resurgence of chikungunya in the twentieth century was first documented in 1953, in the Newala District of Tangaiynika (Tanzania) [8]. The CHIKV continued to spread through the suspected vectors Aedes furcifer/ Aedes cordellieri, to other South African countries, inclusive of Rhodesia (Zimbabwe; 1961, 1962, and 1971) [9].

Epidemics associated with the ECSA lineage subsequently occurred in Cameroon (2006) and Gabon (2007) with Aedes africanus and Aedes albopictus reported as the principal vectors, respectively [10]. In Gabon in 2007, concurrent CHIKV and dengue fever epidemics were also experienced, with CHIKV transmission linked to the $A$. albopictus mosquito [11]. 
The IOL is thought to have evolved from the ECSA genotype [7]. The IOL strain originated in coastal Kenya in 2004 and 2005 (affecting 75\% of the Lamu Island's population, via the vector Aedes aegypti) and then spread to the Reunion Island (affecting one-third of the population) and was subsequently introduced to other islands of the Indian Ocean and continental India, via the vector $A$. albopictus $[1,5-7,12]$. The CHIKV IOL then spread onward to South East Asia [12].

It is believed that the 2007 outbreak in Italy was initiated through the importation of the CHIKV by a traveler from Reunion Island [13]. Local transmission in Reunion Island was then established with $A$. albopictus as the vector [13]. Other countries in which international travel facilitated the spread of CHIKV included France (from travelers from Reunion Island; 77\%), Comoros (14\%), and Mauritius (9\%) [14]. Autochthonous transmission in France, however, was not detected until the year 2010, in association with A. albopictus [15]. Studies have reported a high efficiency of transmission of CHIKV in the temperate climates by the $A$. albopictus species [15].

There are several Aedes species which are competent in the transmission of the CHIKV, with $A$. aegypti and emerging populations of $A$. albopictus identified as responsible vectors in Asia [16]. The Asian strain identified in Thailand in 1958 was transmitted by the suspected vector, A. aegypti [1]. This Asian strain was also reported in outbreaks in India (1962-1965) and Southeast Asia (1958-1960 and 1962-1964), also in association with the $A$. aegypti mosquito [17]. Epidemics of the 1980s and 1990s in Southeast Asian countries (Philippines, Thailand, Myanmar, and Indonesia) were associated with the Asian endemic/epidemic CHIKV lineage. Since then, the Asian endemic/epidemic CHIKV lineage has continued to circulate sporadically, transmitted primarily among humans by $A$. aegypti and was again documented in the 2006 outbreak in Malaysia [1, 7].

Emergence of an IOL strain with resulting replacement of the endemic Asian strain occurred during the Southeast Asia epidemics of 2006-2009 [1, 7]. It is thought that the E1 envelope glycoprotein mutation of the endemic Asian genotype resulted in the decreased adaptability of the CHIKV to A. albopictus, with decreased transmission, and the facilitation of CHIKV evolution and strain replacement [18].

\section{THE CARIBBEAN}

The Caribbean region continues to encounter challenges with the control of mosquito populations including $A$. aegypti and other Aedes species. The Aedes mosquito was introduced to the Caribbean through the African slave trade [19]. Following its introduction, a significant increase in the $A$. aegypti population density was associated with the intercontinental exchange activities of the Second World War [20]. Public health interventions of National Health Ministries and the Pan American Health Organization in the 1950s and 1960s successfully reduced A. aegypti vector indexes by 1972 [19]. This success, however, was short lived and the re-infestations of the Latin American and Caribbean regions by A. aegypti in the late 1970s was accompanied by the introduction of $A$. albopictus in the early 1980s to some Caribbean countries [19]. Although both $A$. aegypti and A. albopictus may be found in the Caribbean, A. aegypti remains the principal vector responsible for the transmission of CHIKV and dengue in this region [21]. 
To date, the CHIKV lineage identified in the 2014 Caribbean outbreak belongs to the old Asian lineage [6]. The presence of the Asian lineage CHIKV, compounded by a naïve Caribbean population and high prevalence of A. aegypti, makes the probability of establishment of endemicity of chikungunya in the Caribbean high. This risk of establishment of endemicity extends to most tropical and subtropical regions of Latin America areas and the southern USA, which is presently experiencing challenges with $A$. aegypti re-infestation.

In the months preceding the Caribbean's first case, China and the Philippines accounted for $27.5 \%$ of travelers into the Caribbean [22]. There were ten cases reported in Spain from travelers from Haiti and Dominica Republic during April to June 2014 [23]. The expansion of the CHIKV to North and South America from the Caribbean is of great concern. Khan et al. [22], in their review of air travel from the Caribbean, noted that the final destination of $52.1 \%$ of international travelers from the chikungunya-infected Caribbean territories was the USA [22]. The most likely cities to be travelled to from the Caribbean were New York (13.8\%), Paris (11.7\%), Miami (7.8\%) and San Juan, Puerto Rico (3.9\%) [22]. It is expected that the change of climatic conditions, compounded by the increase of the warmer weather in temperate zones, will facilitate the further spread of this disease. The months June through to November are designated as the "hurricane season" in the Caribbean, or "the wet season". The wet season has been shown to be associated with the increased breeding of the A. aegypti mosquitos [24].

Florida reported its first two cases of autochthonous CHIKV transmission in July 2014 and, as of September 9, 2014, remains the only US state with autochthonous transmission [25]. Florida now has eight cases of local transmission and 184 travel-associated laboratory-confirmed chikungunya cases as reported to ArborNET [25].

The impact of the introduction of CHIKV into the Caribbean region, a known tourist destination exchange of an estimated 20 million persons annually of which 9 million are US residents, remains to be seen [22]. The acquisition of CHIKV by travelers to the Caribbean enhances the spread to neighboring Caribbean countries and globally [25]. As of epidemiological week 35, among the Caribbean countries affected, those with the highest incidence rates (incidence/100,000 population) include: Guadeloupe $(16,465)$, Martinique $(15,087)$, Saint Martin (French part 13,401), Saint Barthelemy $(11,707)$, Dominica $(5,068)$, Dominican Republic $(4,128)$, and Haiti (627) (Fig. 1) [26].

The emergence of chikungunya in the Caribbean unfolds a story of the dynamic evolution and interaction of microbes and risk factors underlying the determinants of health. The interaction of economic trade and its role in the transmission of vectors and infectious agents needs to be reviewed and policies reinforced and implemented. The management of this disease extends beyond chikungunya to all potential arboviral diseases.

Continued education to increase the awareness of this disease is needed to curtail the population growth of mosquitoes and to mitigate the spread of chikungunya by travelers to the USA and other regions. Improved awareness of the epidemiology and clinical manifestations will enhance patient management and timely reporting to respective authorities. Preventative measures and epidemiological monitoring of the evolving CHIKV epidemic in the Caribbean must be improved and sustained. 
This article does not contain any new studies with human or animal subjects performed by any of the authors.

\section{ACKNOWLEDGMENTS}

We acknowledge Nicola Nelson, Medical Student, University of the West Indies, Mona, Jamaica, for her contribution with Fig. 1. No funding or sponsorship was received for this commentary or publication of this article. Both authors meet the ICMJE criteria for authorship for this manuscript, take responsibility for the integrity of the work as a whole, and have given final approval for the version to be published.

Conflict of interest. Lizette Mowatt and Sandra T. Jackson have no conflict of interest to declare with respect to this article.

Compliance with ethics guidelines. This article does not contain any new studies with human or animal subjects performed by any of the authors.

Open Access. This article is distributed under the terms of the Creative Commons Attribution Noncommercial License which permits any noncommercial use, distribution, and reproduction in any medium, provided the original author(s) and the source are credited.

\section{REFERENCES}

1. Weaver SC. Arrival of chikungunya virus in the new world: prospects for spread and impact on public health. PLoS Negl Trop Dis. 2014;8:e2921.

2. Cassadou S, Boucau S, Petit-Sinturel M, Huc P, Leparc-Goffart I, Ledrans M. Emergence of chikungunya fever on the French side of Saint Martin island, October to December 2013. Euro Surveill. 2014;19:(pii: 20752).
3. Centers for Disease Control and Prevention. Chikungunya in the Americas. Available from: http://www.cdc.gov/chikungunya/geo/americas. html. Accessed Sept 12, 2014.

4. Johansson MA, Powers AM, Pesik N, Cohen NJ, Staples JE. Nowcasting the spread of chikungunya virus in the americas. PLoS One. 2014;9:e104915.

5. Thiboutot MM, Kannan S, Kawalekar OU, et al. Chikungunya: a potentially emerging epidemic? PLoS Negl Trop Dis. 2010;4:e623.

6. Lanciotti RS, Valadere AM. Transcontinental movement of Asian genotype chikungunya virus [letter]. Emerg Infect Dis. 2014;20:1400-2.

7. Volk SM, Chen R, Tsetsarkin KA, et al. Genomescale phylogenetic analyses of chikungunya virus reveal independent emergences of recent epidemics and various evolutionary rates. $\mathrm{J}$ Virol. 2010;84:6497-504.

8. Ross RW. The Newala epidemic. III. The virus: isolation, pathogenic properties and relationship to the epidemic. J Hyg (Lond). 1956;54:177-91.

9. Jupp PG, Kemp A. What is the potential for future outbreaks of chikungunya, dengue and yellow fever in southern Africa? S Afr Med J. 1996;86:35-7.

10. Peyrefitte CN, Rousset D, Pastorino B, et al. Chikungunya virus, Cameroon, 2006. Emerg Infect Dis. 2007;13:768-71.

11. Demanou M, Antonio-Nkondjio C, Ngapana E, et al. Chikungunya outbreak in a rural area of Western Cameroon in 2006: a retrospective serological and entomological survey. BMC Res Notes. 2010;3:128.

12. Kariuki Njenga M, Nderitu L, Ledermann JP, et al. Tracking epidemic chikungunya virus into the Indian Ocean from East Africa. J Gen Virol. 2008;89:2754-60.

13. Rezza G, Nicoletti L, Angelini R, et al. CHIKV study group. Infection with chikungunya virus in Italy: an outbreak in a temperate region. Lancet. 2007;370:1840-6.

14. Parola P, de Lamballerie X, Jourdan J, et al. Novel chikungunya virus variant in travelers returning from Indian Ocean islands. Emerg Infect Dis. 2006;12:1493-9.

15. Vega-Rúa A, Zouache $\mathrm{K}$, Girod R, Failloux AB, Lourenço-de-Oliveira R. High level of vector competence of Aedes aegypti and Aedes albopictus from ten American countries as a crucial factor in the spread of Chikungunya virus. J Virol. 2014;88:6294-306. 
16. Pialoux G, Gaüzère BA, Jauréguiberry S, Strobel M. Chikungunya, an epidemic arbovirosis. Lancet Infect Dis. 2007;7:319-27.

17. Rao TR. Immunological surveys of arbovirus infections in South-East Asia, with special reference to dengue, chikungunya, and Kyasanur Forest disease. Bull World Health Organ. 1971;44:585-91.

18. Tsetsarkin KA, Chen R, Leal G, et al. Chikungunya virus emergence is constrained in Asia by lineagespecific adaptive landscapes. Proc Natl Acad Sci. 2011;108:7872-7.

19. Dick OB, San Martin JL, Montoya RH, del Diego J, Zambrano B, Dayan GH. Review: the history of dengue outbreaks in the Americas. Am J Trop Med Hyg. 2012;87:584-93.

20. Rudnick A. Aedes aegypti and haemorrhagic fever. Bull World Health Organ. 1967;36:528-32.

21. Nasci RS. Movement of chikungunya virus into the Western Hemisphere. Emerg Infect Dis. 2014;20:1394-5.

22. Khan K, Bogoch I, Brownstein JS, et al. Assessing the origin of and potential for international spread of chikungunya virus from the Caribbean. PLoS Curr. 2014;6:(pii: ecurrents.outbreaks.2134a0a7bf37fd8d 388181539fea2da5).

23. Requena-Méndez A, García C, Aldasoro E, et al. Cases of chikungunya virus infection in travellers returning to Spain from Haiti or Dominican Republic, April-June 2014. Euro Surveill. 2014;19:20853.

24. Reiskind MH, Lounibos LP. Spatial and temporal patterns of abundance of Aedes aegypti L. (Stegomyia aegypti) and Aedes albopictus (Skuse) [Stegomyia albopictus (Skuse)] in southern Florida. Med Vet Entomol. 2013;27:421-9.

25. Centers for Disease Control and Prevention. Chikungunya virus in the United States. Available from: http://www.cdc.gov/chikungunya/geo/unitedstates.html. Accessed Sept 12, 2014.

26. Pan American Health Organization/World Health Organization (AHO/WHO). Number of Reported Cases of Chikungunya Fever in the Americas, by Country or Territory 2013-2014, Epidemiological Week/EW 35 Available from: http://www.paho.org/ hq/index.php?option=com_topics\&view $=$ rdmore\& $\mathrm{tt}=\mathrm{PAHO} \% 2 \mathrm{FWHO}+$ Data\%2C+Maps+and+Statistics $\& i d=5927 \&$ tp=\&Itemid=40931\&lang=en. Accessed Sept 12, 2014. 